\title{
Fostering Voluntary Contributions to a Public Good:
}

A Large-Scale Natural Field Experiment at Wikipedia

\author{
By JANA GALLUS*
}

\section{Management Science, Forthcoming}

This natural field experiment tests the effects of purely symbolic awards on volunteer retention in a public goods context. The experiment is conducted at Wikipedia, which faces declining editor retention rates, particularly among newcomers. Randomization assures that award receipt is orthogonal to previous performance. The analysis reveals that awards have a sizeable effect on newcomer retention, which persists over the four quarters following the initial intervention. This is noteworthy for indicating that awards for volunteers can be effective even if they have no impact on the volunteers' future career opportunities. The awards are purely symbolic, and the status increment they produce is limited to the recipients' pseudonymous online identities in a community they have just recently joined. The results can be explained by enhanced self-identification with the community, but they are also in line with recent findings on the role of status and reputation, recognition, and evaluation potential in online communities. JEL codes: C93, M52, H41.

* Dr. Jana Gallus, Harvard Kennedy School, Harvard University. 79 John F. Kennedy Street, Cambridge, MA 02138. Phone: 1 (857) 928 4081. Email: jana_gallus@hks.harvard.edu.

Acknowledgments: I am most grateful to Bruno S. Frey, Gregor Martynus, Patrick Borer, Christoph Engel, Hansruedi Steinauer and Nando Stöcklin for their outstanding advice and support. I also wish to thank Max Bazerman, Iris Bohnet, Margaret McConnell, Reto Cueni, Carsten De Dreu, Victor Ginsburgh, Kai Konrad, Siegwart Lindenberg, Margit Osterloh, Andrew Oswald, Lasse Steiner, Georg von Krogh, and Carl Christian von Weizsäcker for their most helpful comments. The author acknowledges financial support from the Schweizerische Gemeinnützige Gesellschaft (SGG), and from the Center for Research in Economics, Management and the Arts (CREMA), Switzerland. The experiment was reviewed and approved by the Research Directors of CREMA. 
Wikipedia is an undisputed success story. It is the largest online encyclopedia, and its content is provided and curated by voluntary contributors (editors). As of May 2015, more than 55 million $^{1}$ registered editors have voluntarily contributed to this public good. Wikipedia is the world's sixth most popular website ${ }^{2}$ and comprises more than 35 million encyclopedic articles ${ }^{1}$ in 288 different languages $^{3}$ (see also Greenstein and Zhu 2012). Notwithstanding its tremendous and surprising ${ }^{4}$ success, Wikipedia is severely threatened by declining retention rates, in particular among new contributors (Wikimedia 2011a, Halfaker et al. 2013).

Many organizations relying on volunteers face this problem of attrition. People's initial motivations may often not suffice to sustain contributions over the medium to long run. Voluntary commitments have become increasingly fleeting because fewer and fewer volunteers are willing or able to commit to an organization for an extended period of time (Macduff 2005). This confronts volunteer-dependent organizations with the challenge of fostering the behavior of their members without, however, crowding out their intrinsic and image motivations with the rewards they choose to employ (see Gneezy et al. 2011 for a discussion of when incentives do and do not work to motivate pro-social behavior). The organizations have to strike a delicate balance between the nature and salience of the rewards, and the self-determinedness and self-perception of volunteers (Frey and Goette 1999, Falk and Kosfeld 2006, Ariely et al. 2009). They can neither bind their members with contractual agreements, nor can they pay volunteers in the same way they can pay employees. Employing small monetary rewards that accommodate their cash constraint is often even inferior to using no cash rewards at all (Gneezy and Rustichini 2000). Non-monetary alternatives have to be employed to motivate volunteers to stay.

The existing literature is largely silent on the effects and potential of purely symbolic rewards, in particular awards, for pro-social behavior. However, it can be observed that throughout history, the provision of honor to volunteers, for instance with orders of merit, has played an important role in most if not all societies. Awards provide an opportunity to "repay" volunteers in a non-monetary currency that may cater to their initial motivations (e.g., seeking honor). There are nowadays plenty of honors given for pro-social behavior, ranging from state honors (e.g., the President's Volunteer Service Award in the US) to distinctions such as the prestigious Florence Nightingale Medal given by the International Committee

\footnotetext{
${ }^{1}$ https://meta.wikimedia.org/wiki/List_of_Wikipedias\#Grand_Total (accessed May 24, 2015).

${ }^{2} \mathrm{http}: / / \mathrm{www}$.alexa.com/siteinfo/wikipedia.org?range $=5 \mathrm{y} \& \operatorname{size}=$ large $\& \mathrm{y}=\mathrm{t}($ May 24, 2015).

${ }^{3} \mathrm{https}$ ://meta.wikimedia.org/wiki/List_of_Wikipedias (May 24, 2015).

${ }^{4}$ The puzzle that the existence of privately provided public goods poses to theory has intrigued economists for a long time (e.g., Olson 1965). Many analyses have been devoted to the motivations underlying such pro-social behavior, and there is now a rich literature building on behavioral research (Gaechter 2014 presents the central findings of recent research on pro-sociality). Studies focusing on motivations to contribute to online public goods are, e.g., Benkler (2002), Lerner and Tirole (2002), and Lakhani and von Hippel (2003). Von Krogh and von Hippel (2006) provide a useful review.
} 
of the Red Cross, to well-respected awards bestowed by private organizations, such as the Eagle Palms awarded by Boy Scouts of America.

These awards are extrinsic, non-monetary motivators. In the terminology of Bénabou and Tirole (2003, p. 504), they correspond to "discretionary" or "ex post" rewards, as opposed to "promised" or "ex ante" contingent incentives (e.g., innovation prizes). Awards differ from monetary rewards mainly in that they impose little material cost on the giver; they do not require an exact definition and measurement of performance; they are less likely to crowd out the recipient's intrinsic motivation; and they are more suitable for establishing special ties of loyalty and respect between the giver and the recipient (Frey 2007). The publicity as well as the selective and official nature of their bestowal, often involving a prestigious award committee, differentiate awards from positive feedback, personal praise, and gift exchange (Frey and Gallus 2014).

Research on awards has only recently gained momentum in economics and management (e.g., Ginsburgh 2003, Besley 2005, Frey 2005, Rablen and Oswald 2008, Malmendier and Tate 2009, Kosfeld and Neckermann 2011, Ashraf et al. 2014, Chan et al. 2014, Neckermann et al. 2014, Gallus and Frey 2015; see Frey and Gallus 2015 for a survey). It is confronted with two main problems: the clean identification of causality in the field, and the isolation of the purely symbolic dimensions of awards. Merely observing the superior performance of award recipients does not establish whether the award had any effect, since juries are meant to select the candidates who are deemed the best. True randomization is difficult to institute in the field because award-giving institutions are reluctant to relinquish control of the selection process.

The context of Wikipedia makes it possible to examine the causal effects of awards while ruling out material and career-related benefits that awards might entail; individuals tend to operate anonymously under pseudonyms (Wikimedia 2011b). Most studies on awards in the field involve monetary pay, even if only to remunerate subjects for their participation in the experiment. However, the mere presence of financial rewards may interact with the award's effects (Heyman and Ariely 2004). The award given to members of the treatment group on top of their regular pay may, for instance, add meaning to the latter. Since the present experiment does not involve any transfers of money, such possible interactions of awards with money are excluded.

To test the prediction that purely symbolic awards increase newcomer retention on Wikipedia, a new award scheme is implemented, with a committee of senior practitioners to establish the award's reputation. Each month, all newly contributing Wikipedia editors are subjected to a basic screening (to filter out vandals, for example), after which a fixed number of individuals are randomly allocated into the treatment group. An award is posted on their personal page and their name is announced on the official award page, embedded in a national Wikipedia portal. The experimental design allows for a 
straightforward identification of causality by basic mean-comparison tests. The study spans more than eleven months and comprises observations on 4,007 individuals.

The key findings derived from the analysis are that awards can positively and sustainably impact individual behavior even if they do not entail any material or career-related benefits. They seem to be powerful motivators even if the status increment they produce is limited to a community the award recipients have just recently joined; only the award recipients themselves know that they are the individuals behind the pseudonyms that were awarded. The purely symbolic awards increase the share of editors remaining active in the following month by 20 percent $(p=0.000)$. They also raise the share of authors who continue to directly contribute content to articles by 13 percent $(p=0.017)$. In contrast to previous results on gift exchange involving money (Gneezy and List 2006), the symbolic awards' effect persists even over longer time periods. The retention rate among the group of award recipients continues to significantly exceed that of the control group in each of the four quarters following the initial award bestowal.

One possible explanation for the finding that symbolic awards significantly increase retention is that awards induce their recipients to self-identify as members of the community of Wikipedians (a name commonly used for Wikipedia editors). The results on indirect community work done behind the scenes (e.g., coordination and maintenance work) support this conjecture; the awards significantly raise the fraction of newcomers willing to fulfill these tedious but necessary tasks, which are more likely to be assumed by editors who self-identify with the community (e.g., Butler et al. 2007, Kittur et al. 2009, Zhu et al. 2012). Other explanations are provided by recent studies on the role of status and reputation, recognition, and evaluation potential in online communities. The relevance of these explanations is supported by anecdotal evidence from recipients' direct responses to the award and, in the case of status and reputation concerns, by data on social signaling. The persistence of the treatment effect over the year following the intervention is most likely also supported by success-breeds-success dynamics triggered by the initial award.

The present field experiment adds insights to the literature on motivation and rewards in that (i) it is able to establish the causal effect of awards on their recipients' subsequent behavior; (ii) monetary and career related benefits from receiving the award are ruled out; (iii) the award scheme created mirrors institutionalized award schemes as observed in practice (i.e., with regular intervals, fixed numbers, repeated bestowals over a long-term horizon, a hall of fame, a reputable jury and the prestige of a national portal); (iv) the status and reputational capital provided by the award are limited to a specific community, and (v) newcomers are examined, who have not yet been socialized in this community.

\section{Experimental Setup}




\section{A. Background on Wikipedia}

Over the fourteen years since its launch in 2001, Wikipedia has become an established online information repository. ${ }^{5}$ The English and German language versions of Wikipedia draw more than 10.7 million and 1.2 million views per hour, respectively. ${ }^{6}$ Articles are only one part of the project, however. Wikipedia is composed of several areas of activity (called "namespaces") that categorize the different contributions editors can make; grouping for instance all article edits, all file uploads or all contributions to Wikipedia-related meta issues (such as policy design). Every single page has its discussion room ("talk" page) on which editors (called "users") can exchange comments and communicate with each other. Contributors also have a personal user page where they can introduce themselves to the community, as well as a corresponding talk page that serves as a platform for communicating with others. Contributors' activities can thus take many different forms.

To improve quality and fight vandalism, a multitude of standards and rules have gradually been established. New editors wanting to contribute to Wikipedia therefore have to comply with an increasingly complex regulatory framework. Non-compliance with established standards often leads to quick deletion of one's work, be it by other editors or even by automated tools (Morgan et al. 2013). Today, newcomers are more likely to be greeted with a warning rather than a welcome message (Pinchuk 2011), harsh criticism being no exception (Kraut et al. 2012). While reverts (deletions) help preserve quality, they substantially decrease newcomers' willingness to further contribute to the project (Halfaker et al. 2011). Given a diminishing number of topics that do not yet have a Wikipedia entry, new editors often have to fit their contribution into an existing article and defend it in front of more tenured editors keeping watch over their field of expertise (Suh et al. 2009).

In the German language Wikipedia, where this experiment is conducted, newcomers' contributions even have to be screened and confirmed by established editors before being publicly visible. As a result, it can take a considerable time until new editors see the product of their work appear on Wikipedia. The German language Wikipedia is the second-oldest after the English Wikipedia and ranks among the largest Wikipedia language versions ${ }^{7}$ in terms of article numbers (more than 1.8 million as of May 2015 ${ }^{8}$ ), contributors (more than 2.1 million registered accounts ${ }^{9}$ of editors mostly based in Germany, Austria, and Switzerland) and usage (over 1 million views per hour ${ }^{9}$ ).

\footnotetext{
${ }^{5}$ Collaborations between Wikipedia and prestigious research and state entities are no exception (Butler 2008). Already in 2008, The Economist argued: "IT IS the biggest encyclopedia in history and the most successful example of "user-generated content" on the internet" available at http://www.economist.com/node/10789354 (June 16, 2013 ). ${ }^{6} \mathrm{http}: / /$ stats.wikimedia.org/EN/Sitemap.htm (July 24, 2013).

${ }^{7} \mathrm{https}$ ://meta.wikimedia.org/wiki/List_of_Wikipedias (May 24, 2015).

${ }^{8} \mathrm{https}$ ://de.wikipedia.org/w/index.php? ${ }_{\text {title}}=$ Spezial:Statistik\&action=raw (May 24, 2015$)$.

${ }^{9} \mathrm{http}: / /$ stats.wikimedia.org/DE/ (as of March 31, 2015).
} 


\section{B. The Experimental Design}

"[W]orking closely with practitioners" is listed as one of the three central advantages of field experiments by List and Rasul $(2010,105)$. The present study both lends support to this assertion and emphasizes that practitioners' endorsement is most likely to be vital for any such endeavor. The backing and trust of several highly reputable community members were central to this experiment. These contacts were established via telephone calls, which were followed up by regular roundtable meetings with a group of editors willing to tackle the retention problem with the help of the experiment. They became official founding members of the project, which was thus institutionalized under the umbrella of the Swiss national Wikipedia portal, ${ }^{10}$ providing the award with considerable repute and a formal character. The award's official page is displayed and described more closely in Appendix A (see Appendix A1 for a screenshot of the translated page). The page briefly describes the award, how it was developed at several roundtable meetings, and what was the idea behind its creation; namely, to honor new editors and their valuable contributions to the German language Wikipedia. The names of the Wikipedians behind the program are also given. The description does not contain any explicit performance criteria for getting the award, other than that the editors have made their first contributions to the German language Wikipedia in the previous month; it is mentioned that there were more than 4,000 newcomers as potential candidates in a given month. The text does not say that randomization was used to select who out of the final sample of deserving candidates would win the award. It also does not announce that the awards' effects would be evaluated so as to preserve the advantages of a natural field experiment (Harrison and List 2004), i.e., that subjects remain in their natural environment and that their behavior is not distorted by their awareness of the experiment. Below the descriptive text, the respective month's list of award winners is displayed.

The experiment proceeds in four steps (see Table A1 in the Online Appendix). First, on the 6th of every month, a data dump of the German language Wikipedia is obtained, where contributors are identified by an Internet Protocol (IP) address at the time they connect to the Internet, as well as their username and ID if they register an account on Wikipedia. The author is responsible for making the decision about whom to bestow with the first level award ("Edelweiss with Star"), while the core project members evaluate the previous winners and out of these select the recipients for the second and third level awards (2 Star and 3 Star). A computer script is used to identify all new editors who have made their first edit to an article in a given month (approximately 3,000) and submit them to a basic screening, whereby algorithms single out those editors who are not blocked ${ }^{11}$ and who have contributed at least twice, with a minimum of five days

\footnotetext{
${ }^{10}$ Wikipedia portals coordinate work on specific topics related to the respective portal's thematic focus.

${ }^{11}$ See, e.g., Choi et al. (2010, p. 110): "Some users were blocked by Wikipedia because of their vandalistic edits [...]. We excluded those users."
} 
between their first and last edit. This increases the chances that editors actually return to their account and see that they have received an award (if they belong to the treatment group). ${ }^{12}$ Only registered editors are considered for the experiment; ${ }^{13}$ "bots" (automated tools) are excluded.

Second, the remaining editors (approximately 500) are examined one by one to exclude vandals, advertisers, secondary accounts ("sockpuppets"), group accounts (including those created by organizations) and accounts of Wikimedia employees according to a rulebook developed for this purpose. ${ }^{14}$ For this step, an algorithm was developed that flags an editor if specific keywords are found on his or her user page. Only editors are retained who have made at least one contribution to an article that is still visible at the day of the screening, i.e., that has not been deleted, whereby only articles are considered that are not tagged for deletion (as, e.g., in Zhu et al. 2013). This careful screening process was developed in consultation with experienced community members. It helps ensure that members of the resulting pool of candidates would in principle all deserve a small newcomer award for their first efforts to contribute to Wikipedia.

From the pool of remaining editors (approximately 370), 150 award recipients are randomly selected (treatment group). In a fourth and last step, on the morning of the 12th of the given month, the list of winners is posted on the award's page and a text accompanied by a graphic award is placed on the awardees' talk pages, informing them that there were over 4,000 newcomers, i.e., potential candidates, in the previous month (see Appendix A2). A Wikipedia account bearing the name of the award was created for the purpose of making these posts, which are publicly visible.

The award scheme closely mirrors institutionalized award schemes as observed in practice, with regular intervals, fixed numbers, repeated bestowals over a long-term horizon, a hall of fame, a reputable jury and the prestige of a national portal; these attributes clearly differentiate the awards from personal feedback and informal rewards, as studied for instance by Restivo and van de Rijt $(2012,2014)$ in the context of Wikipedia. ${ }^{15}$

\footnotetext{
${ }^{12}$ This condition drastically reduces the size of the subject pool since, as shown by Panciera et al. (2009, p. 55) for the English Wikipedia, roughly " $60 \%$ of registered users never make another edit after their first 24 hours."

${ }^{13}$ IP addresses are often not permanent. They identify a specific device whereas the same person may contribute via various devices. Moreover, they can map to multiple computers in a network (e.g., in an office) or to a single but public computer, which is used by different persons (Zhang and Zhu 2011).

${ }^{14}$ This is in line e.g. with Walling and Taraborelli (2012), who also "exclud[ed] to the best of [their] knowledge sockpuppets and other categories of spurious accounts."

${ }^{15}$ The authors study barnstars, which are widely used informal peer-to-peer rewards in the English Wikipedia that any one editor can freely and spontaneously give to others. In their experiments, the tokens were distributed anonymously (2014) or by a self-declared "not very active" account (2012), all in a single spell. The authors focus on core contributors (the top 10 percent most productive editors) who have never received such a token despite their high levels of contribution. The two studies yield vastly mixed results. While the top 1 percent most productive editors respond positively to receiving a barnstar, the editors in the 91st to 99th percentile range do not alter their productivity; the barnstars even provoke a decrease in retention among those core contributors.
} 
Wikipedia keeps the history of every edit made by each contributor, including the timestamps. This makes it possible to observe the entire range of activities that contributors engage in (e.g., correcting or writing articles, uploading files), including the correspondence among editors on talk pages. ${ }^{16}$ Thus, the accurateness of the performance measurement is close to that in lab experiments, but the scope of action is not artificially imposed and even social interaction is allowed for and taken into account. At the same time, the Internet context makes it possible to treat each award recipient equally, whereas face-to-face interactions could be subject to variability of emotional expressions and inadvertent signaling by the researcher.

\section{Relevant Outcome Variables}

General activity.-The dependent variable of interest is retention, i.e., whether a newcomer becomes active again in the month following the awarding date - the "original definition of activity" being that at least one edit be made in a given month (Wikimedia 2011a, p. 11). As stated on the Wikimedia research pages, "[t]his metric has commonly been used [...] when examining the 'decline' of participation". ${ }^{17}$ In a supplementary analysis examining treatment effect persistence, the time horizon is extended to consider the quarters (i.e., three-monthly periods) following the intervention. As a robustness check, the general notion of activity is further restricted, ignoring contributions to the project's page and to the editor's own pages so as to make sure that the results are not driven by merely award-related communication.

Direct work on articles.-Retention can also be more narrowly conceived. The most conservative measure of retention would exclusively consider article edits as a form of direct content provision, ignoring all other activities (as, e.g., coordination work or file uploads). A binary variable indicates the shares of the treatment and control groups that remain active in this work dimension.

To ensure that any treatment effect found in the analysis (i.e., a higher retention rate among subjects from the treatment group) is not driven by minor editing activities, the degree of activity is considered as an extension. The Wikimedia research team has developed a categorization of activity levels that can be used to see whether the award also produces editors who are more active in providing content to articles than are subjects in the control group. Authors are divided into four groups according to the number of article edits they make in the following month: those who become inactive, those making 1 to 4 article edits, "active" editors (5-99 article edits), and "very active" editors (100+ article edits). ${ }^{18}$

\footnotetext{
${ }^{16}$ Only the correspondence via email is not observable. However, emails only constitute a minor fraction of the correspondence, as becomes evident e.g. by the following advice: "In general, you should not expect Wikipedians to contact you by email. Instead, check back to the talk page periodically to see if your question has been answered" https://en.wikipedia.org/wiki/Wikipedia:Researching_with_Wikipedia (May 20, 2013).

${ }^{17} \mathrm{http}: / /$ meta.wikimedia.org/wiki/Research:Metrics/survival(t) (May 28, 2013).

${ }^{18}$ See http://meta.wikimedia.org/wiki/Research:Metrics (June 7, 2013).
} 
Since the field experiment focuses on newcomer retention, further performance measures are consciously avoided. In particular, the number of article edits as such is not used as a variable for the analysis, despite its favorable property of being a continuous variable. The measure has several pitfalls (see, e.g., Adler et al. 2008). Most importantly, the experimental treatment may introduce an asymmetry between treatment and control groups that inhibits the use of this measure for the analysis. A person can prepare a whole article and put it on Wikipedia in one edit, while another person may correct minor mistakes in an article and save each single change, thus generating many more edits. Each time the save button is hit, one edit is registered. If the distortions of the edit count measure were distributed equally among treatment and control groups, the measure would be flawed, but the comparative analysis could still be revealing. However, receiving an award may prompt newcomers to make an effort to abide by the community conventions, which explicitly ask each editor to reduce the number of edits made to a single article by collecting and previewing all the changes before saving them. ${ }^{19}$ Thus, the award may in fact lead to a decline in the number of edits made by award recipients. The focus on retention (both broadly and narrowly defined) allows the analysis to circumvent the problems related to such performance measurements.

Indirect community work.-For the discussion of the results, variables capturing volunteers' readiness to fulfill indirect community work help to assess whether increased self-identification with the community and a sense of belonging may provide a partial explanation for the award's effect on retention. Such "mundane but necessary" (Lakhani and von Hippel 2003) coordination and maintenance tasks behind the scenes are more likely to be assumed by editors who self-identify with the community (e.g., Kittur et al. 2009). As Butler et al.'s (2007) survey study suggests, commitment and identification with a community make contributors more motivated to fulfill behind the scenes community maintenance work, which is vital for the community's health (see also Ren et al. 2011, p. 77). Zhu et al. (2012) demonstrate, for the context of Wikipedia, that volunteers become more willing to fulfill maintenance and other unattractive but important tasks if they identify and feel they belong to the group. To operationalize an editor's willingness to fulfill indirect community work, the "active on talk pages" variable assesses whether the editor has made any contributions to the talk pages in Wikipedia. The variable "active on Wikipedia meta pages" captures whether the editor has been involved in the organization of the Wikipedia project itself, designing and discussing policies and guidelines, or doing other administrative work. Two further variables measure whether the newcomer has edited his or her own user page, which is

\footnotetext{
${ }^{19}$ The following illustrates the convention: "It is strongly recommended that you use [the Show preview button] before saving [...] Saving the same article several times in quick succession makes it harder for people to check what changed, and clogs up the page history." https://en.wikipedia.org/wiki/Help:Show_preview (June 18, 2013).
} 
most often employed to introduce oneself to the community, or the personal user talk page, which is usually used to respond to other editors' requests.

Status and reputation concerns.-A further and related explanation for why awards may affect newcomer retention is that they lend reputational capital, enhancing the recipient's social image and status in the community. As a proxy for such status and reputation concerns, data on social signaling is used to estimate the share of award recipients who chose to display the award more prominently by putting it on their personal user page.

\section{Theoretical Background}

It is not clear a priori whether awards have any meaningful motivational effect if they are purely symbolic and given to newcomers to a community. After all, awards with no material value are just pieces of ribbon. In this experiment, not even ribbons are used; the award is just a graphic digital symbol.

Research on social identification suggests that being publicly acknowledged by senior community members and being categorized as a valuable contributor may foster a perception of belonging and selfidentification with the community (see Ren et al. 2011 for an overview of the literature and proposals for encouraging identity-related commitment in online communities). Even purely random assignment to a group can activate social identity and foster unselfish cooperation (Goette et al. 2006). As Karau and Williams (2001, p. 129) suggest in their collective effort model, strengthening individuals' social identification with a group is an effective strategy for enhancing individuals' concern with group outcomes; it enhances liking of the group (see Kraut and Resnick 2011, who draw on this model to develop a framework for encouraging contribution to online communities). Applied to the online context, the result of this increased identification and liking is a higher willingness to fulfill less rewarding coordination and maintenance work (Butler et al. 2007, Kittur et al. 2009, Zhu et al. 2012). However, the categorization as a newcomer might also have the opposite effect and induce award recipients to identify as outsiders and/or feel inferior to the established community members.

Another possible and related explanation for why symbolic awards may foster retention is that they enhance their recipients' status and reputation; i.e., the benefits accruing directly to the individual ("individual outcome" in Kraut and Resnick's 2011 framework). Status is an important social need that individuals strive to achieve (Lindenberg 2013). Award recipients may make an effort to receive further awards in the future. Laboratory studies have shown that subjects are willing to incur costs to attain higher status (Huberman et al. 2004, Charness et al. 2014); they work harder even if they expect to be only privately informed about their rank (e.g., Kuhnen and Tymula 2012). Recent field research provides further support for such concerns about relative standing (Blanes i Vidal and Nossol 2011), and is even arguing for an inherent preference for high rank (Tran and Zeckhauser 2012). Yet, there is also lab and 
field evidence for the sometimes-dampening effects of rank information (see Tran and Zeckhauser 2012 for an overview).

Moreover, status and reputational concerns in the voluntary sector differ from those in workplace environments. On the one hand, in a public goods context where everyone benefits from the individual's contributions, informing people that they do better than average may lead them to conclude that they have "done enough" and should reduce or discontinue their involvement (see Chen et al. 2010 for field experimental evidence from an online community). ${ }^{20}$ On the other hand, honoring new editors for their recent contributions may serve as a cue activating their self-image as a generous individual, leading to increased identity investments in the future (e.g., Bénabou and Tirole 2011). When made public, such interventions providing information about people's contributions can trigger social image concerns (see Kraft-Todd et al. 2015 for a survey of related field experiments). In a field experiment in 30 Dutch churches, Soetevent (2005) finds that removing anonymity significantly increases charitable contributions (see also Andreoni and Petrie 2004 and Rege and Telle 2004 on how unmasking contributors increases public good contributions in the lab). Yet, most observed effects of identifiability can also be driven by aversion from shame, which recent experimental evidence suggests can be a stronger motivation for giving than anticipation of prestige (Samek and Sheremeta 2014). In the present experiment, however, shame is unlikely to play a role since subjects use pseudonyms and the treatment only highlights positive performance. Somewhat more related, therefore, is a field experiment by Lacetera and Macis (2010), showing that medals are effective ex ante incentives for blood donations-but only if they are publicly awarded. It is still unclear whether symbolic awards have a motivating effect if there are no face-to-face interactions, and if the status and reputational value they produce is limited to an online community the person has just started to interact with.

Recognition is a closely related motivational factor (see, e.g., Bradler et al. 2013 on employee recognition). It is particularly effective when coming from peers (e.g., Lerner and Tirole 2002 for the case of open source software development) and when being public, in which case it also caters to social image concerns (see Karlan and McConnell 2014 for field and lab experimental evidence related to charitable donations). Awards provide public recognition, even when restricted to an online context; but when awards are given to new contributors, the recognition does not come from established peers. It comes from members of an as of yet unfamiliar community. Nevertheless, being recognized in the beginning for the first contributions can be an important motivator because it raises self-confidence and shows that one's efforts have a valuable impact on the community's performance and outcomes (Karau and Williams 1993,

\footnotetext{
${ }^{20}$ As Thaler and Sunstein (2008, p. 69) admonish, "If you want to nudge people into socially desirable behavior, do not, by any means, let them know that their current actions are better than the social norm."
} 
Rashid et al. 2006). Such early recognition by community members can moreover motivate recipients to increase their efforts so as to honor the award.

Evaluation potential theory provides a related and most basic rationale for why awards may affect behavior in a public goods context: awards signal to their recipients that their individual inputs are being identified and evaluated (e.g., Harkins and Jackson 1985, Karau and Williams 1993, 2001). Award recipients no longer feel "lost in the crowd" (Latané et al. 1979), but rather experience that they receive a fair share of credit for good performance, even though this performance will be merged with the work done by the millions of other editors. Yet, if recipients perceive the award and performance evaluation as obtrusive or even controlling, their intrinsic motivation can also be crowded out.

\section{Empirical Analysis}

\section{A. Randomization}

At first sight, randomly bestowing awards seems to be an almost impossible endeavor, because awards are designed to be given to individuals who excel in their tasks. However, this experiment shows that it can succeed if two important conditions are fulfilled. Firstly, a basic pre-selection has to exclude obviously undeserving candidates, such as vandals. Secondly, subjects who by chance do not receive the award should be an unidentifiable group who ideally are ignorant of the award's existence. This is why the higher levels of the award could not be randomly bestowed. Non-receipt of the second-level award risks demotivating people belonging to the identifiable group of winners of the first-level award who have made an effort to be honored again but fail to win. Such a decision can hardly be randomized.

Randomization has advantages beyond the identification of a causal effect (Zeitoun et al. 2014). Most importantly, it prevents biased decisions (e.g., based on a jury member's political hue) and discourages strategic manipulation (e.g., awards given for work on a particular issue). Randomization hence gives a wide variety of individuals with different interests and areas of engagement the chance to be honored and to receive attention, which is in line with Wikipedia's concern for diversity. ${ }^{21}$

As a randomization check, Panel A of Table 1 displays the t-tests of the observable variables a jury actively selecting award winners might take as performance criteria (i.e., number of general edits before awarding date, number of article edits, number of different articles edited, number of talk edits). Panel B includes Chi-square tests on binary variables that might predict responsiveness to an award, i.e., if editors had previously created their own user page, responded to messages on their talk page, or were actively

\footnotetext{
21 "Wikipedia also needs more different Wikipedians [so as to] increase the quality and completeness of the encyclopedia [as well as] the likelihood that any new member of the community will find like-minded collaborators and feel like they fit in" (Morgan et al. 2013, p. 8).
} 
participating in discussions on talk pages more generally (for a similar reasoning, see Zhang and Zhu 2011, p. 1609). Panel $\mathrm{C}$ shows the t-test of the "treatment immediacy" variable, which predicts the likelihood that editors would notice their award receipt. ${ }^{22}$ The more days that have passed since an editor's last activity, the less likely is the editor to take note if an award is posted on his or her talk page (e.g., Zhu et al. 2013, Restivo and van de Rijt 2014).

TABLE 1 - RANDOMIZATION CHECK

\begin{tabular}{|c|c|c|c|}
\hline & $\begin{array}{l}\text { Treatment } \\
\text { (SD; Min; Max) }\end{array}$ & $\begin{array}{l}\text { Control } \\
\text { (SD; Min; Max) }\end{array}$ & Difference \\
\hline \multicolumn{4}{|l|}{ A. Performance measures (ex ante) } \\
\hline total \# of edits (mean) & $\begin{array}{c}24.10 \\
(64.11 ; 0 ; \quad 1918)\end{array}$ & $\begin{array}{c}25.17 \\
(62.09 ; 0 ; 1026)\end{array}$ & $\begin{array}{c}-1.07 \\
(-0.53)\end{array}$ \\
\hline \# article edits (mean) & $\begin{array}{c}17.15 \\
(56.56 ; \quad 0 ; \quad 1862)\end{array}$ & $\begin{array}{c}17.41 \\
(45.60 ; \quad 0 ; \quad 910)\end{array}$ & $\begin{array}{l}-0.26 \\
(-0.16)\end{array}$ \\
\hline \# different articles edited (mean) & $\begin{array}{c}7.46 \\
(49.43 ; \quad 0 ; \quad 1834)\end{array}$ & 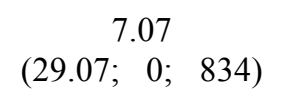 & $\begin{array}{c}0.39 \\
(0.31)\end{array}$ \\
\hline \# talk edits (mean) & $\begin{array}{c}2.91 \\
(8.71 ; \quad 0 ; 113)\end{array}$ & $\begin{array}{c}2.66 \\
(9.78 ; 0 ; \quad 200)\end{array}$ & $\begin{array}{c}0.25 \\
(0.84)\end{array}$ \\
\hline \multicolumn{4}{|l|}{ B. Responsiveness predictors } \\
\hline user page self-edited & $\begin{array}{c}0.20 \\
(\mathrm{SD}=0.40)\end{array}$ & $\begin{array}{c}0.19 \\
(\mathrm{SD}=0.39)\end{array}$ & $\begin{array}{c}0.01 \\
(0.391)\end{array}$ \\
\hline user talk self-edited & $\begin{array}{c}0.16 \\
(\mathrm{SD}=0.36)\end{array}$ & $\begin{array}{c}0.14 \\
(\mathrm{SD}=0.35)\end{array}$ & $\begin{array}{c}0.01 \\
(0.308)\end{array}$ \\
\hline active on talk pages & $\begin{array}{c}0.41 \\
(\mathrm{SD}=0.49)\end{array}$ & $\begin{array}{c}0.38 \\
(\mathrm{SD}=0.49)\end{array}$ & $\begin{array}{c}0.03 \\
(0.089)\end{array}$ \\
\hline $\mathrm{N}$ & 1617 & 2390 & 4007 \\
\hline treatment immediacy (in days) & $\begin{array}{c}15.19 \\
(9.82 ; \quad 1 ; 42)\end{array}$ & $\begin{array}{c}14.73 \\
(9.95 ; 1 ; \quad 78)\end{array}$ & $\begin{array}{c}0.46 \\
(1.43)\end{array}$ \\
\hline $\mathrm{N}$ & 1612 & 2383 & 3995 \\
\hline
\end{tabular}

Notes: Values rounded to 2 decimal places. SD, Min and Max stand for Standard Deviation, Minimum and Maximum. t-values are reported in parentheses in the last column of Panels A and C. Differences were estimated with Chi-square tests in Panel B, where the last column indicates $p$ values in parentheses. For the number of observations $(\mathrm{N})$ in treatment and control groups, see Table Al in the Online Appendix. $\mathrm{N}$ is smaller in Panel $\mathrm{C}$ because some editors' ex ante edits have afterwards been deleted and are thus no longer observable. $* \mathrm{p}<0.05, * * \mathrm{p}<0.01, * * * \mathrm{p}<0.001$.

\footnotetext{
${ }^{22}$ It is not possible to see which editors actually visit the website and see their award. People can visit Wikipedia pages without being logged in to their profiles; even when they are logged in, the pages that they look at without making an edit are not recorded in the dataset.
} 
As expected, before the intervention, the differences are all negligible, point into different directions, and are never even marginally statistically significant. ${ }^{23}$ Before the awarding date, editors in the control and treatment groups are all similarly productive, they are equally likely to respond to others, and they are all similarly likely to detect an award in the event that one was placed on their talk page. The binary outcome variables, i.e., whether an editor stays active at all, or only on article pages, are not included; by definition they should take the value 1 , given that the pre-selection only considers newcomers who have made their first article edit in the previous month.

However, the ordinal variable based on the Wikimedia Foundation's categorization of activity levels, which will be included as an outcome variable, can be used as a further randomization check (the levels of activity being 0 article edits, 1-4 article edits, 5-99 article edits, and 100+ article edits). A WilcoxonMann-Whitney test (see Table B1, Online Appendix B) produces statistically insignificant results $(z=$ 1.169 , Prob $>|z|=0.2426$ ). This again confirms that assignment to treatment and control groups was random.

\section{B. Results}

The analysis considers eleven awarding rounds, from September 2012 to July 2013. Each month, 150 newcomers received the "Edelweiss with Star" award. As of May 2015, when the latest data dump was received, 33 editors ( 2 percent) from the treatment group and 77 editors ( 3 percent) from the control group had been blocked since the awarding date and thus dropped out of the data set. Treatment and control groups therefore comprise 1,617 and 2,390 editors, respectively (see Table A1 in the Online Appendix for an overview of the monthly cohorts).

Thanks to the random assignment of the treatment, potential confounding variables are on average distributed equally between the treatment and control groups. Hence, basic and clearly interpretable mean-comparison tests can be used to see whether the award has a causal effect on retention, both broadly (general activity) and narrowly (direct article work) defined; and if so, what the size of the effect is.

General activity.-Figure 1 plots the shares of editors in the control and treatment groups who become active again in the first month after the awarding date. This basic bar chart indicates that the retention rate is 7 percentage points higher for recipients of the award. The error bars indicate that the 20 percent increase in the retention rate is statistically significant.

\footnotetext{
${ }^{23}$ A power analysis indicates that even a small effect of .2 (see Cohen 1988) would be detected, if it existed, with a probability of .9999975 (one-tailed) given the sample size of the two groups and an alpha error probability of .05.
} 


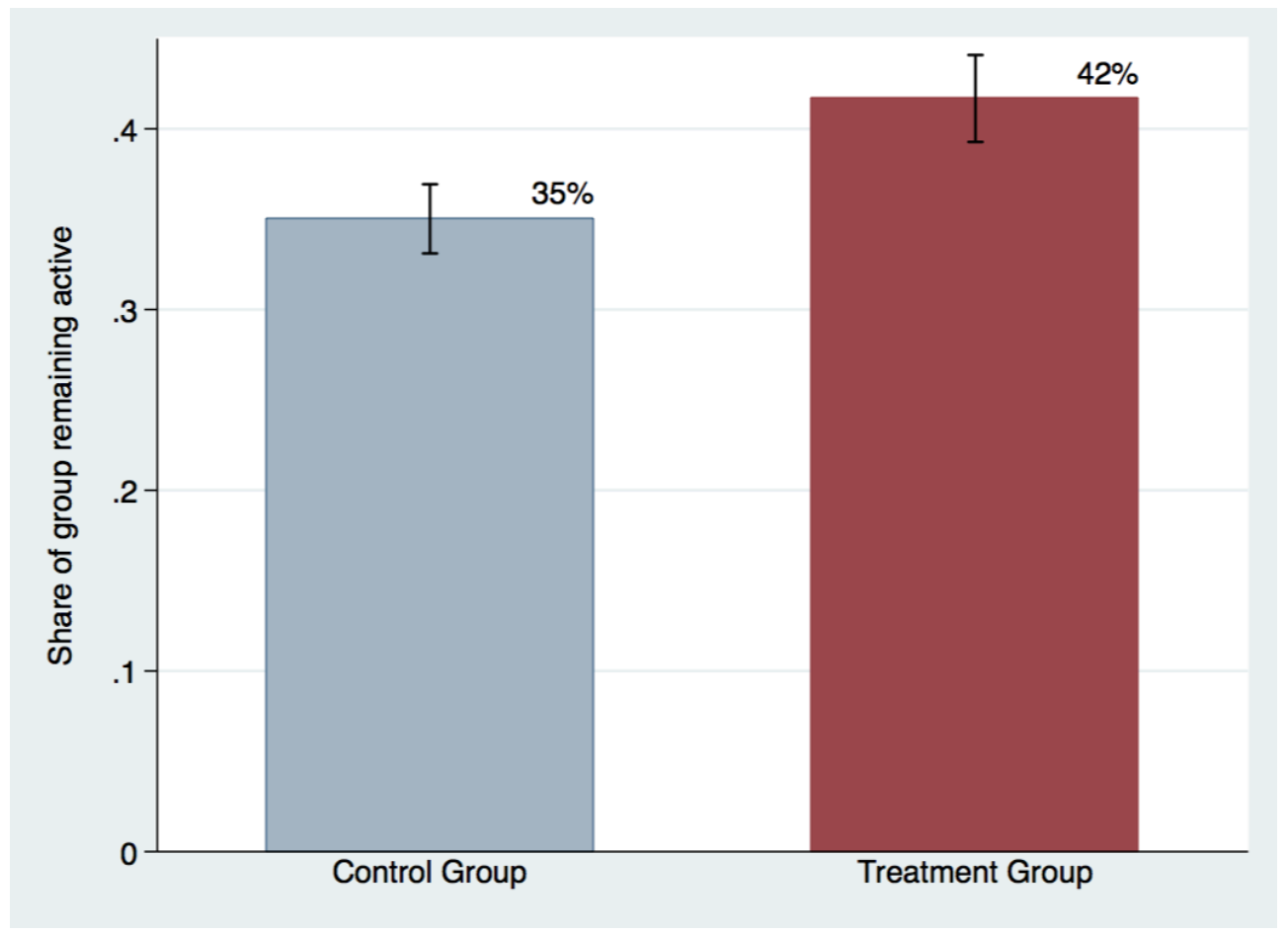

FIGURE 1. MEAN RETENTION RATES

Notes: Focusing on first month after awarding date. Error bars indicate the $95 \%$ confidence intervals.

Table 2 reports the retention rates in the treatment and control groups, as well as the differences between them and the $p$-values resulting from the Chi-square tests. Panel A focuses on the most basic measure of retention, i.e., whether any activity can be observed after the awarding date. Following Figure 1, the first row considers the month after the awarding date and shows that the difference observed in the bar chart is indeed statistically significant at the 99.9 percent level $\left(\chi^{2}(1)=18.22, p=0.000\right)$. 
TABLE 2 - RETENTION EFFECT

\begin{tabular}{|c|c|c|c|}
\hline & $\begin{array}{c}\text { Treatment } \\
\text { (1) }\end{array}$ & $\begin{array}{c}\text { Control } \\
\text { (2) }\end{array}$ & $\begin{array}{c}\text { Difference } \\
\text { (3) }\end{array}$ \\
\hline \multicolumn{4}{|l|}{ A. General activity } \\
\hline active (1st month) & 0.42 & 0.35 & $\begin{array}{c}0.07 * * * \\
(0.000)\end{array}$ \\
\hline active (following 2 months) & 0.49 & 0.43 & $\begin{array}{l}0.06 * * * \\
(0.000)\end{array}$ \\
\hline \multicolumn{4}{|l|}{ B. Direct content provision } \\
\hline active, only article edits ( $1 \mathrm{st}$ month) & 0.36 & 0.32 & $\begin{array}{c}0.04 * \\
(0.017)\end{array}$ \\
\hline active, only article edits ( 2 months) & 0.43 & 0.40 & $\begin{array}{c}0.04 * \\
(0.022)\end{array}$ \\
\hline $\mathrm{N}$ & 1617 & 2390 & 4007 \\
\hline
\end{tabular}

Notes: Average values are rounded to 2 decimal places. $p$-values from Chi-square tests are reported in parentheses. Adjustments for multiple comparisons do not change the significance of any of the tests (see Table B2, Online Appendix B). * ${ }^{*}<0.05, * * p<0.01, * * * p<0.001$.

Row 2 in Panel A (Table 2) extends the period of observation to the 2 months following the intervention to ascertain that the difference observed in row 1 is not due to a temporal substitution effect, i.e., that award recipients do not merely advance their next period of activity to the first month instead of the second after the awarding date. The results in row 2 show that, when considering the 2 months following the intervention, the retention rate in the treatment group still exceeds the retention rate observed in the control group by 6 percentage points ( 49 percent versus 43 percent). This treatment effect of 14 percent is again highly statistically significant $\left(\chi^{2}(1)=12.75, p=0.000\right)$. The award's effect on retention is thus not due to editors resuming their activity earlier than usual because of the award.

Direct work on articles.-When restricting the definition of activity solely to article edits (Table 2, Panel B), the share of award recipients who remain active in this dimension of work amounts to 36 percent in the month following the award bestowal; it is 4 percentage points higher than the retention rate of 32 percent observed in the control group. The award's causal effect, raising the retention rate by 13 percent, is statistically significant at the 95-percent level $\left(\chi^{2}(1)=5.66, p=0.017\right)$. As before, extending the time horizon to the two months following the intervention still produces a significant difference in the retention rates of the two groups (43 percent in the treatment versus 40 percent in the control group).

The analysis of Panel B (Table 2) can be extended to explore whether the award also produces more highly active authors. The Wikimedia Foundation's categorization of activity levels (focusing on article edits) is used as a basis for this part of the analysis. Figure 2 shows the average marginal effects of the 
award for the different levels of article editing activity in the first month after the awarding date, including the respective 95\% confidence intervals. As can be seen in Figure 2, the award's effect on retention is not driven only by minor article editing activity; the share of newcomers who remain active is significantly increased at every level of activity (1-4 edits; 5-99 edits; and $\geq 100$ edits). Figure 2 thus illustrates that the award not only lowers the attrition rate of new authors (as seen in Panel B of Table 2 and in the "inactive" category in Figure 2); it raises the share of editors at every level of activity.

The limitations of the edit count metric have been mentioned above, but transforming the measure into an ordinal variable mitigates the distortionary tendencies and helps ascertain that the award's effect on retention found in Panel B of Table 2 is not due to only minor article editing activity. A Wilcoxon-MannWhitney test (see Table B3, Online Appendix B) also shows the statistical significance of the finding that the treatment group tends to have larger values on the ordinal "degree of activity" variable than the control group $(z$-value $=-2.470$, Prob $>|z|=0.0135) .^{24}$

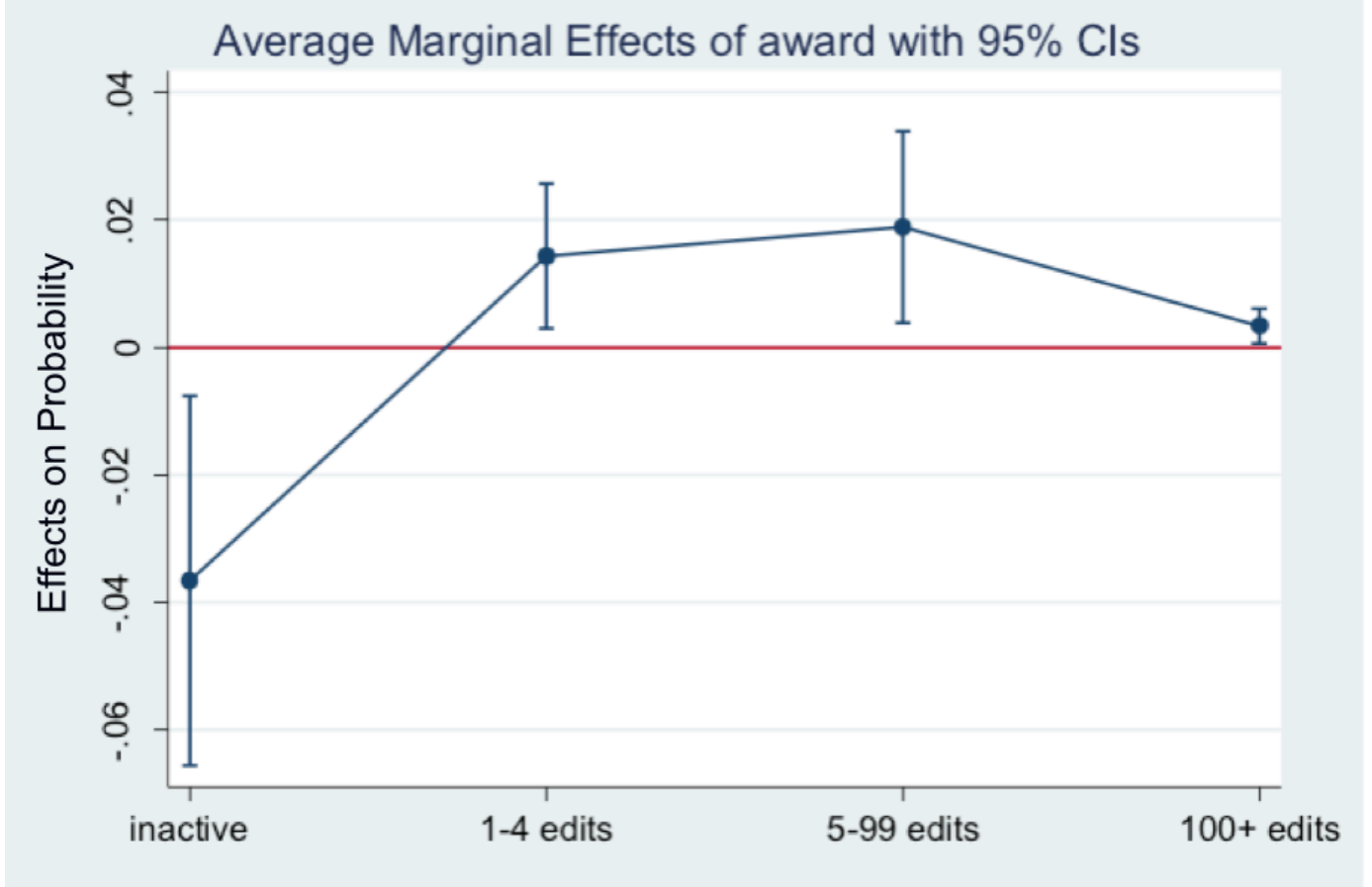

Figure 2. DEGREE OF ARTICLE EDITING ACTIVITY

Notes: First month after awarding date. Error bars indicate 95\% confidence intervals. The figure extends row 1 of Panel B in Table 2 and shows the treatment effect at each level of article editing activity.

\footnotetext{
${ }^{24}$ Mann Whitney only allows one to draw conclusions about the statistical significance of the test. For the effect size, ordered logit is used. The proportional odds ratio of comparing subjects of the control group with award recipients on the level of activity is 1.17764 (Prob $>|z|=0.014$ ), the cut-points being $.7351199,1.708068$, and 3.925069. This means that the odds of high activity (i.e., 4 or more edits) versus the combined lower categories of activity are 1.18 times greater for subjects in the treatment group.
} 
Treatment effect persistence.-The focus of the analysis lies on the first month after the awarding date, for two main reasons. Firstly, four weeks are a long time horizon in the Internet context, where the first 24 hours are highly predictive of an editor's future engagement (e.g., Panciera et al. 2009, Morgan et al. 2013). Previous research on gift exchange has shown that positive effects initially found vanished after the first couple of hours (Gneezy and List 2006). If the award scheme prompts more newcomers to return, this provides an opportunity for other community members to get in contact and involve them more thoroughly in the community. Secondly, and relatedly, recent work on success-breeds-success dynamics in online communities, including on Wikipedia, suggests that positive public peer feedback leads to cascades of positive reinforcement by other community members (van de Rijt et al. 2014; see also Kraut and Resnick 2011, p. 52). It therefore becomes increasingly difficult to look at the direct effect of the award as the time horizon is extended, also because some editors receive further awards over time. Notwithstanding this cautionary note, a supplementary analysis further extending the period of observation is helpful to get an indication of whether the difference in retention rates between the treatment and control groups also persists over the long term. Since the focus on article edits ignores important forms of contribution, such as coordination work which is crucial for the health of the community, the analysis of treatment effect persistence again considers general activity (as in Figure 1 and Panel A of Table 2).

Table 3 shows that, when considering the retention rates in the quarters following the initial award, the difference between treatment and control groups persists and remains significant until and including the fourth quarter after the intervention. Whether on its own or together with reinforcing feedback dynamics, the award provokes an increase in the retention rate by 11 percent (from 47 to 52 percent; $\chi^{2}(1)=9.51, p$ $=0.002$ ), 10 percent (from 31 to 34 percent; $\chi^{2}(1)=4.61, p=0.032$ ), 13 percent (from 24 to 27 percent; $\chi^{2}(1)=4.67, p=0.031$ ), and 13 percent (from 23 to 26 percent; $\chi^{2}(1)=4.33, p=0.037$ ) in quarters $1,2,3$, and 4, respectively, after the intervention. The difference in quarter 5 still points into the expected direction but it is no longer significant $\left(\chi^{2}(1)=1.50, p=0.221\right)$. 
TABLE 3 - TREATMENT EFFECT PERSISTENCE

\begin{tabular}{lccc}
\hline \hline & $\begin{array}{c}\text { Treatment } \\
(1)\end{array}$ & $\begin{array}{c}\text { Control } \\
(2)\end{array}$ & $\begin{array}{c}\text { Difference } \\
(3)\end{array}$ \\
\hline \hline $\begin{array}{l}\text { A. General activity } \\
\text { Quarter 1 }\end{array}$ & 0.52 & 0.47 & $0.05^{* *}$ \\
Quarter 2 & & & $(0.002)$ \\
& 0.34 & $0.03^{*}$ \\
Quarter 3 & & & $(0.032)$ \\
Quarter 4 & 0.27 & 0.24 & $0.03^{*}$ \\
Quarter 5 & 0.26 & 0.23 & $(0.031)$ \\
& & & $0.03^{*}$ \\
\hline \hline $\mathrm{N}$ & 0.21 & 0.20 & 0.02 \\
\hline \hline
\end{tabular}

Notes: Average values rounded to 2 decimal places. $p$-values from Chi-square tests are reported in parentheses. The two higher-level awards, which are not randomly bestowed, fall into quarters 1 and 2; they could be received after months 2 and 5 after the initial award whose effects are being tested. The scheme includes no further awards thereafter. $* p<0.05, * * p<0.01, * * * p<0.001$.

There is so far only limited evidence on the post-intervention persistence of treatment effects in the context of voluntary public goods contributions. The related field experiments that do consider long run post-intervention implications (six months and longer) mostly study treatments targeted at charitable giving (e.g., Meier 2007, Shang and Croson 2009, Landry et al. 2010), and environmental conservation interventions using household-level social comparison messages (Ferraro et al. 2011, Ferraro and Price 2013, Allcott and Rogers 2014). The results of these studies are mixed; while in some cases the effects persist after the treatment's discontinuation, in other cases they vanish or even turn into negative net effects, for instance due to motivation crowding-out. Figuring in the non-negligible costs of some of the interventions, the overall evaluation can become very negative. Symbolic awards are a low-cost intervention. The basic test in Table 3 helps ensure that the positive effect found in the first month after the intervention is not reversed later on. The finding that the retention rate in the treatment group continues to lie significantly above that in the control group in each of the following four quarters indicates that awards have the potential to trigger a dynamic that fosters retention over the long term.

\section{Discussion}

There are various mechanisms through which awards can have a positive effect on newcomer retention, besides the external reinforcement produced by success-breeds-success dynamics. The following discussion considers four major explanations, without disentangling their relative importance: enhanced 
self-identification with the community, status and reputation concerns, recognition, and evaluation potential in online communities.

Self-identification with the community.-Wikipedia editors' willingness to fulfill mundane but important coordination work behind the scenes is taken as a proxy for their self-identification with the community (in line with, e.g., Butler et al. 2007, Zhu et al. 2012). Table 4 presents results on four central measures that reflect whether newcomers are willing to assume such maintenance work and actively engage with the community. Row 1 shows that the award increases the share of newcomers willing to coordinate with others on talk pages, for instance discussing article content or rules, by about 50 percent in the month following the intervention (from less than 13 percent to more than 19 percent; $\chi^{2}(1)=$ 32.85, $p=0.000$ ). The second row indicates that the award also increases the share of editors who participate in the organization of the Wikipedia project, developing guidelines and fulfilling administrative tasks, by 33 percent in the first month after the intervention (from 6 to 8 percent; $\chi^{2}(1)=$ $6.34, p=0.012$ ). The share of newcomers who self-disclose and introduce themselves to the community on their personal user pages is raised by 75 percent (from 4 to 7 percent; $\chi^{2}(1)=18.97, p=0.000$; see row 3), thus providing others with greater opportunities to contact them (e.g., based on the fields of interest indicated on the personal page). Compared to the control group, twice as many award recipients respond to others' requests on their talk pages and thus enter in direct contact with community members ( 8 percent versus 4 percent; $\chi^{2}(1)=34.17, p=0.000$; see row 4 ). These results indicate that enhanced self-identification as a community member may be one important reason for why the awards have such a significant effect on newcomer retention.

TABLE 4 - SOCIAL IDENTIFICATION

\begin{tabular}{lccc}
\hline \hline & $\begin{array}{c}\text { Treatment } \\
(1)\end{array}$ & $\begin{array}{c}\text { Control } \\
(2)\end{array}$ & $\begin{array}{c}\text { Difference } \\
(3)\end{array}$ \\
\hline \hline A. Indirect community work (1st month) & & & \\
active on talk pages & 0.19 & 0.13 & $\begin{array}{c}0.07 * * * \\
(0.000)\end{array}$ \\
active on Wikipedia meta pages & & & $0.02 *$ \\
& 0.08 & 0.06 & $(0.012)$ \\
user page self-edited & & 0.04 & $0.03 * * *$ \\
& 0.07 & & $(0.000)$ \\
user talk self-edited & & 0.04 & $0.04 * * *$ \\
& 0.08 & & $(0.000)$ \\
\hline \hline $\mathrm{N}$ & & 2390 & 4007 \\
\hline \hline
\end{tabular}

Notes: First month after awarding date. Average values rounded to 2 decimal places. $p$-values from Chi-square tests are reported in parentheses. Adjustments for multiple comparisons do not change 
the significance of any of the tests (see Table B2, Online Appendix B). * $p<0.05, * * p<0.01$, *** $p<0.001$.

Status and reputation concerns.-Another possible explanation for the awards' effect on retention is that they lend reputational capital to newcomers, even if that capital is restricted to the online community. To understand whether status and reputation concerns provide a pertinent explanation, data on award recipients' choice to more prominently display the award by putting it on their personal user page is collected. As of May 2015, 58 award recipients from the eleven awarding rounds had put a small template (called "Babel") that had been created by a recipient of the first wave (see Appendix A3) onto their user page; 43 had copied the award graphic or both the graphic and the entire text (Appendix A2) to display it there ( 7 among them also included the small template). Hence, 94 winners (5.8 percent) had chosen to display their receipt of the award more prominently on their user page. This number provides a lowerbound estimate of the relevance of reputation and status concerns; many individuals can be expected to refrain from engaging in active social signaling for fear of diluting the signal of merit.

Recognition.--Awards signal to their recipients that their contributions and effort are being recognized and considered valuable by others. In particular for newcomers, such recognition can raise selfconfidence in a critical learning phase marked by uncertainty. While the experimental setup does not allow the single mechanisms accounting for the awards' motivational effect to be isolated, anecdotal evidence suggests that recognition and enhanced self-confidence are relevant explanations. Several award recipients referred to their feeling of being recognized in their response to the award, which they posted on the award talk page or on their own talk page. Some exemplary quotes are: "Thank you very much for the recognition. I will continue [contributing]!" (in February 2013), "Thank you very much. I have spent much time with Wikipedia. The recognition for this [effort] makes me very happy" (April 2013), "I feel very honored to receive this award. It makes me realize that contributions, even if they may be small, are recognized here" (December 2012), or "Dear friends in Switzerland. I thank you most warmly for this recognition. It is nice that my contributions are positively taken note of in Switzerland. Thanks and kind regards to the Confederates" (in August 2013). The recognition provided by the awards may also strengthen their recipients' confidence and encourage them to embark on more demanding projects, as the following exemplary quote suggests: "Dear Edelweiß-Team, as an absolute newcomer I am very delighted about this award! I initially only wanted to make a few corrections every now and then, but this form of welcoming has highly motivated me! I am now working on my first article... Many heartfelt thanks in retrospect!" (from September 2012; emphasis in original). Although the wording of the award scheme on purpose omits any reference to future expectations, some responses indicate that the recognition provided leads some recipients to want to honor the award and live up to perceived expectations: "Hello Portal Switzerland, a heartfelt Merci vielmal [Swiss German for "many thanks"] for the award, which makes me 
tremendously happy! I will do my best to live up to the honor. Best regards, [...]" (November 2012; as before, author's translation).

Evaluation potential.-Related to the recognition-based explanation, awards also signal to their recipients that their individual inputs for the common good are being identified and evaluated. Recipients no longer feel "lost in the crowd" and instead experience that they receive credit for their inputs. The relevance of this explanation is supported by responses illustrating that some individuals clearly attribute their award receipt to specific contributions they have made, which they perceive to have been evaluated. For instance, one recipient wrote to his mentor: "[...] I received an award from the Portal Switzerland for my first article (Edelweiss with a Star)!! I want to thank you most warmly for mentoring me, since I would not have succeeded in writing the article like that without your help during my first Wiki-steps. As such, a petal of the edelweiss belongs to you; just choose one. Again, thank you and I look forward to our future cooperation!" (from September 2012; emphasis added).

All four explanations, social identification, status and reputation concerns, recognition, and evaluation potential, seem to be important in explaining the motivational effects of symbolic awards. Future research could usefully inform the design of awards by examining the conditions under which the single mechanisms become more or less important. It could also differentiate the relevance of the mechanisms according to different types of award recipients (e.g., based on the degree of previous contributions, seniority, age, gender, professional background), and analyze who is most responsive to receiving symbolic awards.

\section{Robustness}

Two additional binary activity variables are created to ascertain that the central result, that symbolic awards significantly increase newcomer retention (Figure 1), is not merely driven by award-related communication. In line with the analysis in Panel A of Table 2, the two variables record any type of activity. However, the first alternative variable for measuring general activity ignores contributions to the award project's page, and the second variable goes even further in that it also omits edits to the editor's own user and user talk pages.

Panel A in Table B4 (Online Appendix B) presents the results from the Chi-square tests which compare the means of editors who stay active in the month following the awarding date. Excluding the award project's page (row 1) does not change the results from row 1 in Panel A of Table 2. This suggests that award recipients who post a thank you note on the project's page also make other contributions. Additionally excluding editors' own pages somewhat reduces the effect, but still shows a difference of 5 percentage points, which is highly statistically significant $\left(\chi^{2}(1)=11.95, p=0.001\right.$; row 2 in Table B4, Panel A). The treatment's positive effect on retention is hence not produced simply by communication on 
the award. A causal effect of the award on retention can be established even when applying very conservative measures of activity, such as that in row 2 of Table B4 or the one that only considers direct edits to articles (Table 2, Panel B).

Focusing on the more restrictive measure of activity (as in row 2 of Table B4), which excludes the award project's page and editors' own pages, Panel B of Table B4 considers the robustness of the findings on treatment effect persistence. Panel B shows that using this conservative measure of activity leaves the original findings from Table 3 unchanged, i.e., the difference between the treatment and control groups persists in the four quarters following the intervention, and ceases to be significant in the fifth quarter after the awarding date.

Notwithstanding their robustness and statistical significance, the findings from this first study on purely symbolic awards and volunteer retention have to be interpreted with caution. $p$-values are not the sole provider of inferential information; the statistical power of the test and research priors also need to be taken into account. Based on these variables, Maniadis et al. (2014) present a model to calculate the PostStudy Probability $(P S P)$ that a research finding is indeed true. The PSP equals the number of true associations which are declared true divided by the number of all associations which are declared true. Since some of the variables are difficult to specify exactly, it is useful to consider a number of combinations of them to provide meaningful ranges for the PSP. With an $\alpha$ error probability of 0.05 and a power $(1-\beta)=0.99,{ }^{25}$ a conservative prior probability $(\pi)$ of 0.01 yields a PSP of only 0.167 . However, if the prior $(\pi)=0.05$, the PSP is 0.510 and thus crosses the 50 percent threshold. The PSP for prior $\pi$ values of $0.10,0.20,0.35$ and 0.55 is $0.688,0.832,0.914$ and 0.960 , respectively. ${ }^{26}$ As this illustrates, the PSP is increasing in the prior $\pi$. We should hence be cautious not to make overly strong inference from novel and surprising experimental results, even if they are statistically significant. As the framework in Maniadis et al. (2014) highlights, already a few independent replications tremendously increase the PSP.

\section{Concluding Remarks}

While research on the motivations for private contributions to public goods is extensive, little is known about the rewards that help sustain volunteers' contributions without crowding out their intrinsic motivation. Awards such as orders and medals of valor are symbolic rewards that may foster such voluntary contributions. They are certainly a widespread phenomenon. However, any investigation into their causal effects is hindered by their juries' unwillingness to see their authority replaced by random decision-making processes.

\footnotetext{
${ }^{25}$ With a sample size of 4,007 and an $\alpha$ error probability of 0.05 , a power calculation indicates that $(1-\beta)>0.999$.

${ }^{26}$ Note that these results can be simply derived from the basic framework in Maniadis et al. (2014, p. 284, equation 1) since the number of independent researchers exploring the question $(k)=1$ for the present study.
} 
This study presents a large-scale natural field experiment in which an award scheme with fixed intervals and award numbers is institutionalized and randomization is employed to establish clear causal effects of awards on voluntary contributions to a public good. The experiment addresses one of the online encyclopedia's most serious challenges, the retention of new editors. It explores whether purely symbolic awards can be used to increase newcomer retention, even if the status and reputational capital they provide are limited to an online community the award recipient has only recently joined.

The award scheme is shown to have a considerable and statistically highly significant effect on retention. The share of newcomers who remain active in the month after the awarding date is 7 percentage points higher for the treatment group than for the control group. This is a 20 percent increase in the retention rate $(p=0.000)$, from a share of 35 percent to one of 42 percent, which is not driven by a temporal substitution effect or by award-related communication. When solely considering direct contributions to articles, the award also increases the fraction of newcomers who remain active, resulting in a difference of 4 percentage points between treatment and control groups. The 13 percent increase (from 32 percent to 36 percent, $p=0.017$ ) is not driven by minor editing activities; the award increases the shares of authors at all three commonly considered activity levels.

A supplementary analysis of treatment effect persistence indicates that the difference in general retention rates observed between control and treatment groups continues to be significant over the four quarters after the intervention; it becomes insignificant thereafter. The discussion considers four main explanations for the motivational effect of the symbolic awards: increased self-identification as a community member, status and reputational concerns, recognition, and evaluation potential. Additional data (e.g., on social signaling) as well as anecdotal evidence support the relevance of these explanations. Recent research on success-breeds-success dynamics in online communities furthermore suggests that external reinforcement triggered by the award (e.g., additional positive feedback, lower reversion rates) may provide another important explanation, in particular to account for the treatment effect's persistence.

The findings are worth noting not only because the award is costless and has no material implications, but also because it is given to newcomers who operate under pseudonyms that they have only recently adopted. Previous research (Restivo and van de Rijt 2014) has suggested that "rewards may [...] be counterproductive for [editors] who are not already sufficiently embedded within the core contributor community" (p. 459), warning that it can even lead to lower retention. The present study follows the authors' call for further investigation and shows that even new community members can be positively motivated by symbolic rewards, if these convey meaningful signals of appreciation. The estimates are conservative since non-responsiveness to the intervention may be due not only to indifference, but also to unawareness, since some recipients simply do not (or only belatedly) return to their user page and thus do not see that they have won an award (Panciera et al. 2009, p. 55; Morgan et al. 2013, p. 5). 
The analysis focuses on the treatment's effect on newcomer retention and does not consider any possible spillover effects of the award. These are most likely to affect senior editors, since work on Wikipedia is highly content-oriented ${ }^{27}$ and repeat social interaction, if it occurs, tends to take place between newcomers and more experienced editors who help them and answer their questions. The positive effect the award might have on these third parties is exemplified by the quote referenced in the discussion section, where an award recipient thanks his mentor. Just as such additional positive effects are not captured in the evaluation of the award, potential negative effects on non-recipients are also not considered. However, these can be expected to be negligible or even non-existent, since other newcomers are most likely unaware of the award's existence. Moreover, there is no list showing specifically which editors were considered and left without award.

While these considerations suggest that the award program's beneficial impact may well exceed the effects found in this analysis, two limitations should also be noted. Firstly, the value of awards hinges on their rarity; they have to be used sparingly to prevent inflationary tendencies. Awards should therefore be integrated into a broader reward scheme (also including, e.g., thank you gifts and communal events), alongside other forms of providing recognition (e.g., personal praise), to increase retention rates. A promising avenue for future research will be to explore the relationship between awards and other rewards, and that between the value of an award and the quantity and frequency with which it is bestowed. Varying other award parameters, such as the degree of publicity, and considering which volunteer groups are most responsive to symbolic awards would be of equal interest.

Secondly, the experiment is conducted in an anonymous online context. As noted by Zhang and Zhu (2011, p. 1613), an interesting direction for future research will be to examine the findings' generalizability to non-virtual fields and other public goods contexts. However, the results as they stand are important given the increasing penetration of the Internet into professional and private spheres. The finding that anonymous newcomers to an online community are motivated by attention and public social recognition is important and should receive further attention by researchers. It may inform policies dealing with anonymity and its impacts on individual behavior.

\section{REFERENCES}

Adler BT, de Alfaro L, Pye I, Raman V (2008) Measuring author contributions to the Wikipedia. P. 4th Internat. Sympos. on Wikis:1-15.

Allcott H, Rogers T (2014) The short-run and long-run effects of behavioral interventions: experimental evidence from energy conservation. Am. Econ. Rev. 104:3003-3037.

\footnotetext{
${ }^{27}$ As is stated in the description of talk pages, "The purpose of all talk pages is the improvement of Wikipedia as an encyclopedia" https://de.wikipedia.org/wiki/Wikipedia:Diskussionsseiten (June 5, 2015; author's translation).
} 
Andreoni J, Petrie R (2004) Public goods experiments without confidentiality: A glimpse into fundraising. J. Pub. Econ. 88:1605-1623.

Ariely D, Bracha A, Meier S (2009) Doing good or doing well? Image motivation and monetary incentives in behaving prosocially. Amer. Econ. Rev. 99:544-555.

Ashraf N, Bandiera O, Lee S (2014) Awards unbundled: Evidence from a natural field experiment. $J$. Econ. Behav. Organ. 100:44-63.

Bénabou R, Tirole J (2003) Intrinsic and extrinsic motivation. Rev. Econ. Stud. 70:489-520.

Bénabou R, Tirole J (2011) Identity, morals, and taboos: Beliefs as assets. Quart. J. Econ. 126:805-855.

Benkler Y (2002) Coase's Penguin, or, Linux and "The Nature of the Firm". Yale Law J. 112:369-446.

Besley T (2005) Notes on honours. Mimeo, London School of Economics.

Blanes i Vidal J, Nossol M (2011) Tournaments without prizes: Evidence from personnel records. Management Sci. 57:1721-1736.

Bradler C, Dur R, Neckermann S, Non A (2013) Employee recognition and performance: A field experiment. Management Sci. Forthcoming.

Butler B, Sproull L, Kiesler S, Kraut R (2007) Community effort in online groups: Who does the work and why? In Leadership at a Distance, edited by Weisband S, 171-194 (Erlbaum, Hillsdale, NJ).

Butler D (2008) Publish in Wikipedia or perish. Nature News (16 Dec), doi:10.1038/news.2008.1312.

Chan HF, Frey BS, Gallus J, Torgler B (2014) Academic honors and performance. Labour Econ. 31:188204.

Charness G, Masclet D, Villeval MC (2014) The dark side of competition for status. Management Sci. $60: 38-55$.

Chen Y, Harper M, Konstan J, Li SX (2010) Social comparisons and contributions to online communities: A field experiment on MovieLens. Amer. Econ. Rev. 100:1358-1398.

Choi B, Alexander K, Kraut RE, Levine JM (2010) Socialization tactics in Wikipedia and their effects. $P$. ACM Conf. on Computer Supported Cooperative Work:107-116.

Cohen J (1988) Statistical Power Analysis for the Behavioral Sciences, 2nd ed. (Erlbaum, Hillsdale, NJ).

Falk A, Kosfeld M (2006) The hidden costs of control. Amer. Econ. Rev. 96:1611-1630.

Ferraro PJ, Miranda JJ, Price MK (2011) The persistence of treatment effects with norm-based policy instruments: Evidence from a randomized environmental policy experiment. Am. Econ. Rev. 101:318322.

Ferraro PJ, Price MK (2013) Using nonpecuniary strategies to influence behavior: Evidence from a largescale field experiment. Rev. Econ. Stat. 95:64-73.

Frey BS (2005) Knight Fever: Towards an economics of awards. CESifo Working Paper No. 1468.

Frey BS (2007) Awards as compensation. Europ. Management Rev. 4:6-14. 
Frey BS, Gallus J (2014) Awards are a special kind of signal. CREMA Working Paper No. 2014-04.

Frey BS, Gallus J (2015) Towards an economics of awards. J. Econ. Surv. Forthcoming.

Frey BS, Goette L (1999) Does pay motivate volunteers? IEW Working Paper No. 7.

Gaechter S (2014) Human pro-social motivation and the maintenance of social order. In Oxford

Handbook of Behavioral Economics and the Law, edited by Zamir E, Teichman D, 28-60 (Oxford University Press, Oxford).

Gallus J, Frey BS (2015) Awards: A strategic management perspective. Strategic Management J. Forthcoming.

Ginsburgh V (2003) Awards, success and aesthetic quality in the arts. J. Econ. Perspect. 17:99-111.

Gneezy U, List JA (2006) Putting behavioral economics to work: Testing for gift exchange in labor markets using field experiments. Econometrica 74:1365-1384.

Gneezy U, Meier S, Rey-Biel P (2011) When and why incentives (don't) work to modify behavior. $J$. Econ. Perspect. 25:191-209.

Gneezy U, Rustichini A (2000) Pay enough or don't pay at all. Q. J. Econ. 115:791-810.

Goette L, Huffman D, Meier S (2006) The impact of group membership on cooperation and norm enforcement: Evidence using random assignment to real social groups. Amer. Econ. Rev. 96:212-216.

Greenstein S, Zhu F (2012) Is Wikipedia biased? Amer. Econ. Rev. 102:343-348.

Halfaker A, Geiger RS, Morgan JT, Riedl J (2013) The rise and decline of an open collaboration system: How Wikipedia's reaction to popularity is causing its decline. Amer. Behav. Scientist 57:664-688.

Halfaker A, Kittur A, Riedl J (2011) Don't bite the newbies: How reverts affect the quantity and quality of Wikipedia work. P. 7th Internat. Sympos. on Wikis and Open Collaboration:163-172.

Harrison GW, List JA (2004) Field experiments. J. Econ. Lit. 42:1009-1055.

Heyman J, Ariely D (2004) Effort for payment: A tale of two markets. Psycholog. Sci. 15:787-793.

Huberman BA, Loch C, Önçüler A (2004) Status as a valued resource. Soc. Psychol. Quart. 67:103-114.

Karau SJ, Williams KD (1993) Social loafing: A meta-analytic review and theoretical integration. J. Pers. Soc. Psychol. 65:681-706.

Karau SJ, Williams KD (2001) Understanding individual motivation in groups: The collective effort model. In Groups at Work, edited by Turner ME, 113-141 (Erlbaum, Mahwah, NJ).

Karlan D, McConnell MA (2014) Hey look at me: The effect of giving circles on giving. J. Econ. Behav. Organ. 106:402-412.

Kittur A, Pendleton B, Kraut RE (2009) Herding the cats: The influence of groups in coordinating peer production. P. 5th Internat. Sympos. on Wikis and Open Collaboration:1-9.

Kosfeld M, Neckermann S (2011) Getting more work for nothing? Symbolic awards and worker performance. Amer. Econ. J.: Microeconom. 3:86-99. 
Kraft-Todd G, Yoeli E, Bhanot S, Rand D (2015) Promoting cooperation in the field. Curr. Opin. Behav. Sci. 3:96-101.

Kraut RE, Kittur A, Zhu H, He J, Zhang A (2012) Effects of feedback on participation in Wikipedia: http://meta.wikimedia.org/wiki/Research:Effects_of_Feedback_on_Participation_in_Wikipedia.

Kraut RE, Resnick P (2011) Encouraging contribution to online communities. In Building Successful Online Communities, edited by Kraut RE, Resnick P, 21-76 (MIT Press, Cambridge, MA).

Kuhnen CM, Tymula A (2012) Feedback, self-esteem, and performance in organizations. Management Sci. 58:94-113.

Lacetera N, Macis M (2010) Social image concerns and prosocial behavior: Field evidence from a nonlinear incentive scheme. J. Econ. Behav. Organ. 76:225-237.

Lakhani KR, von Hippel E (2003) How open source software works: "Free" user-to-user assistance. Research Pol. 32:923-943.

Landry CE, Lange A, List JA, Price MK, Rupp NG (2010) Is a donor in hand better than two in the bush? Evidence from a natural field experiment. Am. Econ. Rev. 100:958-983.

Latané B, Williams K, Harkins S (1979) Many hands make light the work: The causes and consequences of social loafing. J. Pers. Soc. Psychol. 37:822-832.

Lerner J, Tirole J (2002) Some simple economics of open source. J. Industrial Econ. 50:197-234.

Lindenberg S (2013) Social rationality, self-regulation, and well-being: The regulatory significance of needs, goals, and the self. In Handbook of Rational Choice Social Research, edited by Wittek R, Snijders TAB, Nee V, 72-112 (Stanford University Press, Stanford, CA).

List JA, Rasul I (2010) Field experiments in labor economics. In Handbook of Labor Economics, edited by Ashenfelter OC, Card DE, 103-228 (Elsevier, San Diego, Amsterdam).

List JA, Shaikh AM, Xu Y (2016) Multiple hypothesis testing in experimental economics. NBER Working Paper No. 21875.

Macduff N (2005) Societal changes and the rise of the episodic volunteer. In Emerging Areas of Volunteering, edited by Brudney JL, 49-62 (ARNOVA, Indianapolis, IN).

Malmendier U, Tate G (2009) Superstar CEOs. Quart. J. Econ. 124:1593-1638.

Maniadis Z, Tufano F, List JA (2014) One swallow doesn't make a summer: New evidence on anchoring effects. Am. Econ. Rev. 104: 277-290.

Meier S (2007) Do subsidies increase charitable giving in the long run? Matching donations in a field experiment. J. Eur. Econ. Assoc. 5:1203-1222.

Morgan JT, Bouterse S, Stierch S, Walls H (2013) Tea \& sympathy: Crafting positive new user experiences on Wikipedia. Conf. on Computer Supported Cooperative Work.

Neckermann S, Cueni R, Frey BS (2014) Awards at work. Labour Econ. 31:205-217. 
Olson M (1965) The Logic of Collective Action: Public Goods and the Theory of Groups (Harvard University Press, Cambridge, MA).

Panciera K, Halfaker A, Terveen L (2009) Wikipedians are born, not made: A study of power editors on Wikipedia. P. ACM Conf. on Supporting Group Work:51-60.

Pinchuk M (2011) The rise of warnings to new editors on English Wikipedia. Wikimedia Blog (May 2).

Rablen MD, Oswald AJ (2008) Mortality and immortality: The Nobel Prize as an experiment into the effect of status upon longevity. J. Health Econ. 27:1462-1471.

Rashid AM, Ling K, Tassone RD, Resnick P, Kraut R, Riedl J (2006) Motivating participation by displaying the value of contribution. SIGCHI Conf. on Human Factors in Computing Systems:955-958.

Rege M, Telle K (2004) The impact of social approval and framing on cooperation in public good situations. J. Pub. Econ. 88:1625-1644.

Ren Y, Kraut R, Kiesler S, Resnick P (2011) Encouraging commitment in online communities. In Building Successful Online Communities, edited by Kraut RE, Resnick P, 77-124 (MIT Press, Cambridge, MA).

Restivo M, van de Rijt A (2012) Experimental study of informal rewards in peer production. PloS ONE 7:e34358.

Restivo M, van de Rijt A (2014) No praise without effort: Experimental evidence on how rewards affect Wikipedia's contributor community. Inf. Comm. Soc. 17:451-462.

Shang J, Croson R (2009) A field experiment in charitable contribution: The impact of social information on the voluntary provision of public goods. Econ. J. 119:1422-1439.

Soetevent AR (2005) Anonymity in giving in a natural context: A field experiment in 30 churches. $J$. Pub. Econ. 89:2301-2323.

Suh B, Convertino G, Chi EH, Pirolli P (2009) The singularity is not near: Slowing growth of Wikipedia. P. 5th Internat. Symposium on Wikis and Open Collaboration:8.

Thaler RH, Sunstein CR (2008) Nudge: Improving Decisions about Health, Wealth, and Happiness (Yale University Press, New Haven \& London).

Tran A, Zeckhauser R (2012) Rank as an inherent incentive: Evidence from a field experiment. J. Pub. Econ. 96:645-650.

van de Rijt A, Kang SM, Restivo M, Patil A (2014) Field experiments of success-breeds-success dynamics. P. Natl. Acad. Sci. 111:6934-6939.

von Krogh G, von Hippel E (2006) The promise of research on open source software. Management Sci. 52:975-983.

Walling S, Taraborelli D (2012) Is this thing on? Giving new Wikipedians feedback post-edit. Wikimedia Blog (September 24). 
Wikimedia (2011a) Editor trends study: Results. Wikimedia Strategic Planning (May 14).

Wikimedia (2011b) Semi-annual survey of Wikipedia editors. Wikimedia Foundation (April).

Zeitoun H, Osterloh M, Frey BS (2014) Learning from ancient Athens: Demarchy and corporate governance. Acad. Management Perspect. 28:1-14.

Zhang X, Zhu F (2011) Group size and incentives to contribute: A natural experiment at Chinese Wikipedia. Amer. Econ. Rev. 101:1601-1615.

Zhu H, Kraut RE, Kittur A (2012) Organizing without formal organization: group identification, goal setting and social modeling in directing online production. P. ACM Conf. on Comp. Supp. Cooperat. Work:935-944.

Zhu H, Zhang A, He J, Kraut RE, Kittur A (2013) Effects of peer feedback on contribution: A field experiment in Wikipedia. P. SIGCHI Conf. on Human Factors in Computing Systems:2253-2262. 


\section{APPENDIX}

\section{APPENDIX A: THE AWARD}

The design of the award page was modeled on that of the Swiss national Wikipedia portal, the banner of which is prominently displayed on top of the website (see Appendix A1). The award and a link to its page also appear on the front of the Portal Switzerland page. The text on the award page briefly describes the award and the idea behind it, without giving any details on performance criteria other than the condition that the editors have each made their first contributions to the German language Wikipedia in the previous month (what kind of contribution is not defined). The aim of the award is declared, i.e., "to honor new [editors] and their precious contributions to the German language Wikipedia. They deserve our thanks and recognition." The names of some of the team members are provided so that questions, suggestions or criticism can be directed to them. The page mentions that there were more than 4,000 newcomers in the previous month, and then displays the month's lists of recipients of the 1,2 and 3 Star awards, as well as a link to the lists of former recipients (similar to a hall of fame). On the bottom of the page, a small template (called "babel", Appendix A3) that was created by a recipient of the first wave is offered for those interested to copy and put it onto their personal user page. ${ }^{28}$

The award that is put on recipients' talk pages resembles a medal and displays a Swiss national symbol (an edelweiss flower) and a golden star, adorned by a laurel wreath. The text informs its recipients that there were more than 4,000 newcomers in the previous month (see Appendix A2 below). Award recipients usually post their reactions underneath the award on their talk page or on the project's talk page. Some put the babel or the entire award graphic on their user page.

\footnotetext{
${ }^{28}$ Editors frequently display such templates on their user pages to provide information on their language skills, for instance. See https://en.wikipedia.org/wiki/Wikipedia:Babel (June 27, 2013).
} 


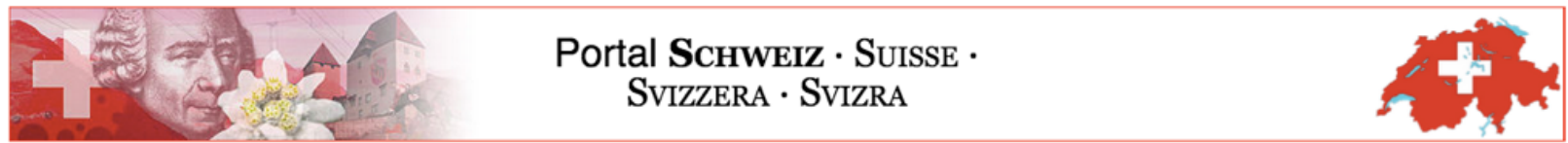

The Award „Edelweiss with Star" honors on a monthly basis a selection of those users who have made their first contributions to the German-language Wikipedia in the previous month. Awardees who continue their engagement can receive two further awards besides the original award: "Edelweiss with two Stars" and "Edelweiss with three Stars".

The award recipients shall be considered as representative for all those new users who have constructively contributed to our common project. Welcome!

Idea and Realization

With the Edelweiss-Award, a group of authors of the Portal Switzerland wishes to honor new users and their valuable contributions to the German-language Wikipedia. They deserve our gratitude and our recognition.

The idea for such an award emerged from the Wikipedia roundtable in Zurich. After that, the award "Edelweiss" was for the first time bestowed in July 2012. The suggestions that were made after the first round of bestowals were intensively discussed and carefully integrated into the present award concept on consecutive roundtable meetings.

In case of questions, suggestions or criticism, please feel free to directly contact one of the users present at the roundtable meetings (for instance, [7 user names]). We are eager to preserve the positive spirit of this award and to abstain from dragging new users directly into discussions.

\section{Edelweiss with Star}

Out of more than 4,000 candidates who were for the first time active in the German-language Wikipedia in May 2015, we have awarded the following users in early June.

$\begin{array}{ll}X Y Z & X Y Z \\ X Y Z & X Y Z \\ X Y Z & X Y Z \\ X Y Z & X Y Z \\ X Y Z & X Y Z \\ X Y Z & X Y Z \\ X Y Z & X Y Z \\ \square \sim 7 & \checkmark v 7\end{array}$

$X Y Z$
$X Y Z$
$X Y Z$
$X Y Z$
$X Y Z$
$X Y Z$
$X Y Z$

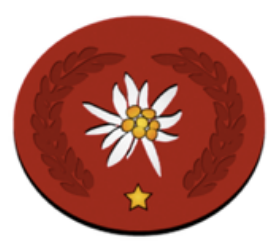

Note: "XYZ" is a placeholder for the pseudonyms of the award winners, which are displayed there.

\section{Appendix A2. Award template inserted on user talk pages (author's translation)}

\section{An Edelweiss for You}

Hello [User Name], out of more than 4,000 new authors in the month of [May] you belong to those who have already enriched Wikipedia through their participation. As a small thank-you for your contributions to the German language Wikipedia we hereby present you with an Edelweiss from Switzerland. With best regards -- The Project Edelweiss-Award in the Portal Switzerland, 12 [June 2015]

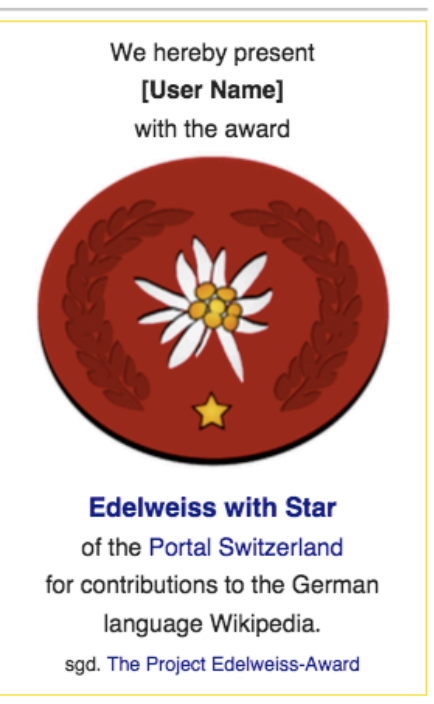

Appendix A3. Babel template (author's translation) 
Fostering Voluntary Contributions to a Public Good

A Large-Scale Natural Field Experiment at Wikipedia

\section{ONLINE APPENDIX}




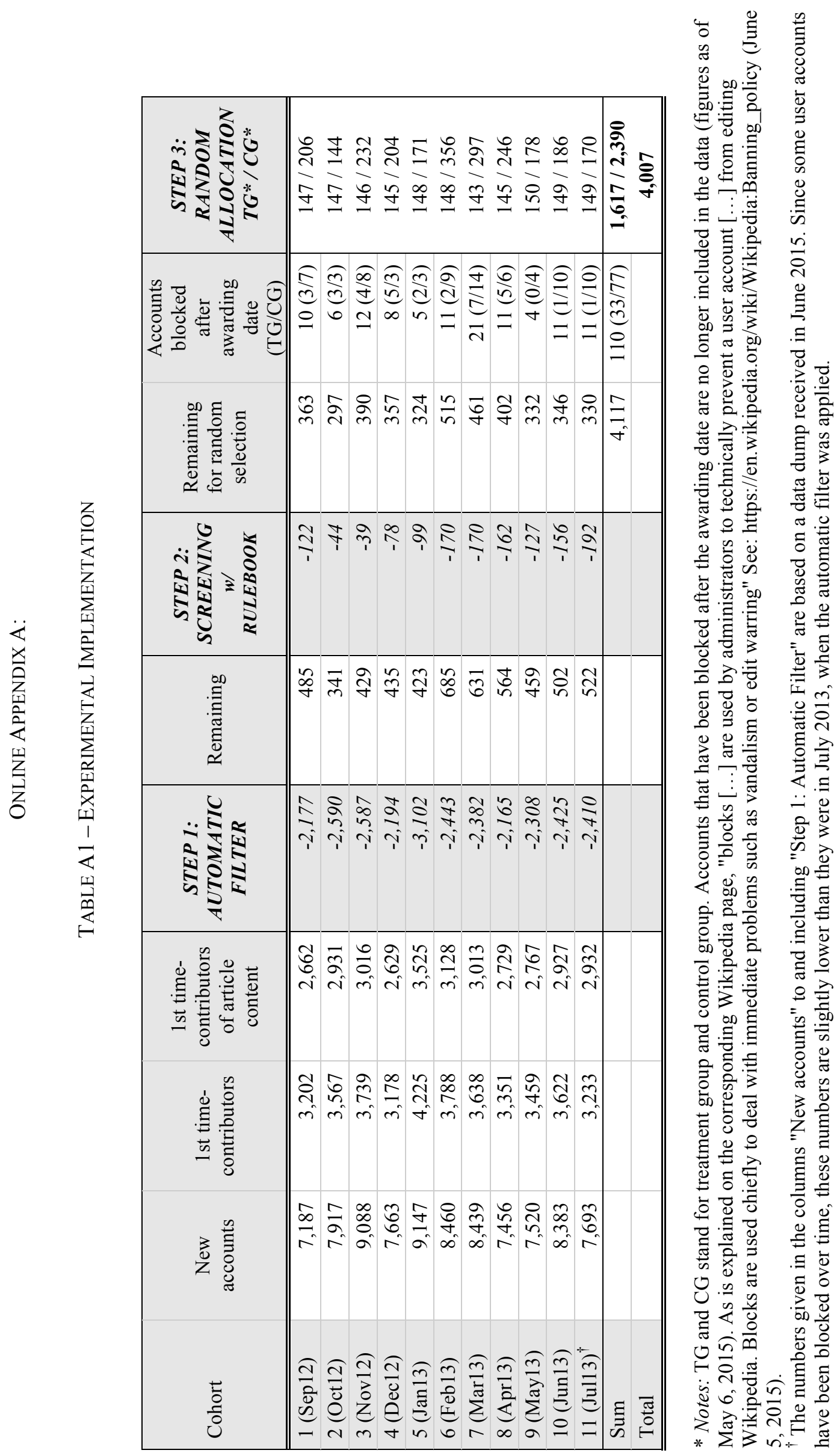




\section{ONLINE APPENDIX B}

\section{TABLE B1 - RANDOMIZATION CHECK}

Ordinal variable: Level of article editing activity before awarding date.

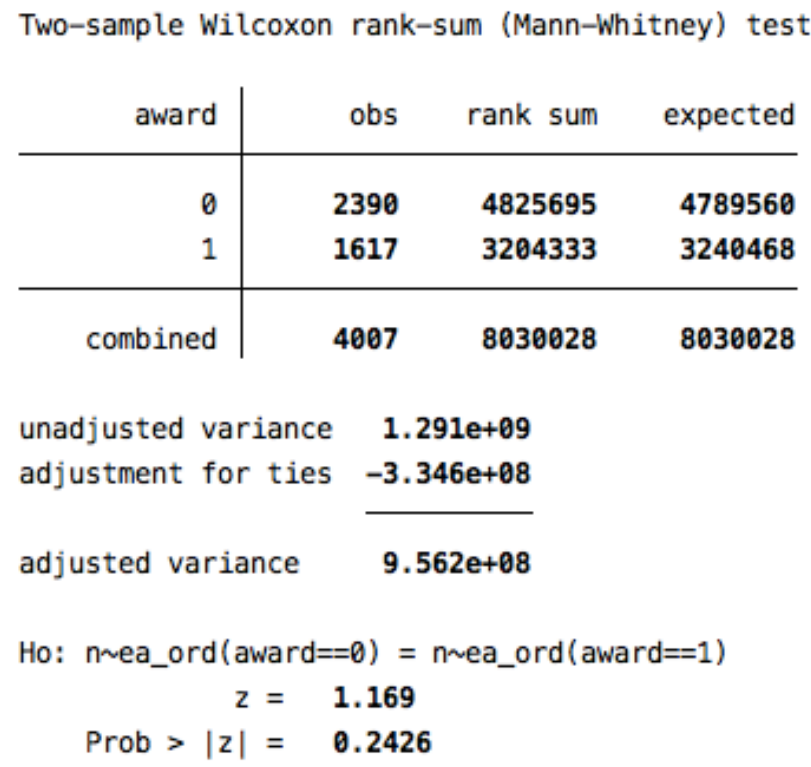

TABLE B2 - MULTIPLE TESTING ADJUSTMENTS

\begin{tabular}{lccc}
\hline \hline Outcome & DI & \multicolumn{2}{c}{$p$-values } \\
\hline \hline & & Unadj. & Multiplicity Adj. \\
\cline { 2 - 4 } active & 0.0666 & $0.0003^{* * *}$ & $0.0003^{* * *}$ \\
active (following 2 months) & 0.0572 & $0.0003^{* * *}$ & $0.0003^{* * *}$ \\
active, only article edits & 0.0363 & $0.016^{*}$ & $0.0317^{*}$ \\
active, only article edits (2 months) & 0.0364 & $0.0197^{*}$ & $0.0197^{*}$ \\
degree of activity, only article edits & 0.0641 & $0.0167^{*}$ & $0.027^{*}$ \\
active on talk pages & 0.0664 & $0.0003^{* * *}$ & $0.0003^{* * *}$ \\
active on Wikipedia meta pages & 0.0204 & $0.0113^{*}$ & $0.0327^{*}$ \\
user page self-edited & 0.0310 & $0.0003^{* * *}$ & $0.0003^{* * *}$ \\
user talk self-edited & 0.0441 & $0.0003^{* * *}$ & $0.0003^{* * *}$ \\
active, excl. award pages & 0.0666 & $0.0003^{* * *}$ & $0.0003^{* * *}$ \\
active, excl. award \& own pages & 0.0537 & $0.001^{* *}$ & $0.0027^{* * *}$ \\
\hline \hline
\end{tabular}

Notes: The $p$-value adjustments in column 4 are based on the procedure and code developed by List et al. (2016). DI refers to "difference in means". If not indicated otherwise outcomes refer to the first month after the initial intervention. $* p<0.05, * * p<0.01, * * * p<0.001$. 
TABLE B3 - EFFECT ON LEVEL OF ACTIVITY

1 st month after awarding date, article edits only.

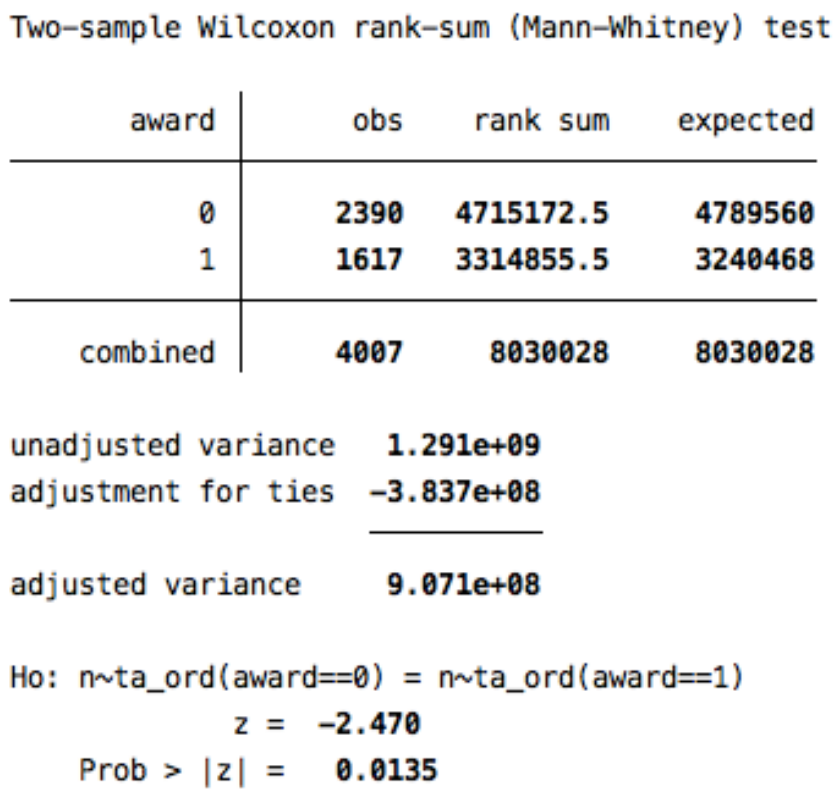

TABLE B4 - ROBUSTNESS CHECKS

\begin{tabular}{lccc}
\hline \hline & $\begin{array}{c}\text { Treatment } \\
(1)\end{array}$ & $\begin{array}{c}\text { Control } \\
(2)\end{array}$ & $\begin{array}{c}\text { Difference } \\
(3)\end{array}$ \\
\hline \hline A. General activity (1st month) & & & \\
active, excl. award pages & 0.42 & 0.35 & $\begin{array}{c}0.07^{* * *} \\
(0.000)\end{array}$ \\
& & & $0.05^{* * *}$ \\
active, excl. award \& own pages & 0.40 & 0.35 & $(0.001)$ \\
\hline B. Treatment effect persistence. DV: active, excl. award \& own pages & & \\
Quarter 1 & 0.51 & 0.47 & $0.04^{*}$ \\
Quarter 2 & 0.34 & 0.30 & $(0.013)$ \\
& & & $0.03^{*}$ \\
Quarter 3 & 0.26 & 0.24 & $0.027)$ \\
Quarter 4 & & & $(0.048)$ \\
& 0.26 & 0.23 & $0.03^{*}$ \\
Quarter 5 & & & $(0.032)$ \\
& 0.21 & 0.20 & 0.02 \\
\hline \hline $\mathrm{N}$ & & & $(0.232)$ \\
\hline \hline
\end{tabular}

Notes: Average values rounded to 2 decimal places. DV stands for dependent variable. $p$-values from Chi-square tests are reported in parentheses. Table $B 2$ above also presents adjustments for multiple testing related to Panel A, which tests multiple outcomes falling into the same time period as the outcomes of the main analysis. The significance of the tests remains unchanged.

$* p<0.05, * * p<0.01, * * * p<0.001$. 